\title{
KNOWLEDGE REGARDING MENARCHE AMONG THE UPPER PRIMARY SCHOOL GIRLS
}

Mrs. Smitha Rani $S^{*}$ | Mrs. Anju Priya P V ${ }^{* *}$

*Vice Principal, SP Fort College of Nursing, Thiruvananthapuram, Kerala India.

**Assistant Professor, SP Fort College of Nursing, Thiruvananthapuram, Kerala, India. DOI: http://doi.org/10.47211/tg.2020.v07iws01.002

Received $12^{\text {th }}$ June 2020, Accepted $18^{\text {th }}$ June 2020, Available online $30^{\text {th }}$ June 2020.

\section{ABSTRACT:}

A descriptive study was conducted "To assess the knowledge regarding menarche among upper primary school girls of Fort Girl's Mission High School. Fort, Trivandrum". The objectives of the study were to assess the knowledge of upper primary school girls regarding menarche, to determine the association between menarche with selected demographic variables and to provide planned health teaching program on menarche and puberty. Descriptive design was used as the research design. Convenient sampling technique was adopted and 50 upper primary girls from $U P$ section were the study participants. The tool used for data collection consists of demographic variables and structured questionnaire to assess the knowledge regarding menarche. The data was collected by reporting method. Data were tabulated and analyzed by using descriptive and inferential statistics. Result showed that, only 14\% had good knowledge, $82 \%$ reported average knowledge and $4 \%$ were having poor knowledge on menarche.

Key Words: Knowledge, Menarche, Upper primary school girls.

\section{ABOUT AUTHORS}

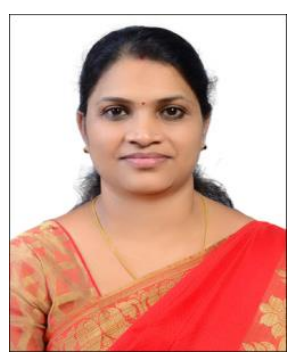

Author Mrs. Smitha Rani S is working as Vice Principal in SP Fort College of Nursing, Thiruvananthapuram, Kerala, India. She has many publications to her credit.

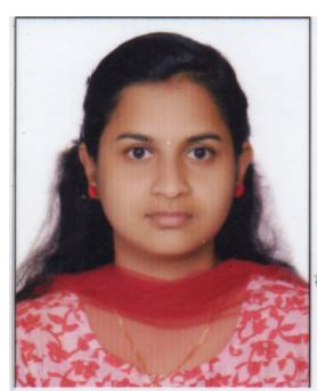

Author Mrs. Anju Priya P V is an Assistant Professor in SP Fort College of Nursing, Thiruvananthapuram, Kerala, India. 


\section{INTRODUCTION:}

Menarche is the major landmark of puberty for females. Puberty is the process of physical change by which a child's body matures into adult and the body capable of sexual reproduction. Menarche follows the appearance of secondary sexual characteristics. It is initiated by hormonal signals from the brain to the ovaries. Physical growth, i.e. height and weight accelerate in the first half of puberty and is completed when the child has developed on adult body.

The age of menarche or first menstruation is an important maturity indicator for assessment of development status of pubertal female. Age menarche is a complex process and involves both genetic and external factors. The external factors include place of residence, physical activity, body composition, nutritional pattern, body mass index, socio-economic status, stress, migration, ethnicity and chronic illness. Many of these factors are inter related to each other. The onset of first menstrual period indicates full sexual maturity, although full biological and emotional maturity occurs much later.

Concerns about the normality in development of puberty and the initiation of menstrual patterns are the most common problem among girls. They frequently have difficulty in assessing what represents normal pubertal changes and menstrual cycle or pattern of bleeding. The upper primary school girls, whose menarche is a new physiological change that occurs in their puberty needs special attention and care.

In most of the girls below 12 years of age has less knowledge about menarche, physiological changes occurs in their body, psychological changes and also the hormonal variations which has been occur. Early menarche leads to earlier sexual intercourses and is a risk factor for adolescent depression. Girls are associated with a variety of negative physical and psychological changes related to menstruation, reflecting both misconception and ignorance and fear of being different from peers as well. Training on how to deal with the maturity process is a necessity for the safe passage of this critical period. Hence the researcher felt the need to assess the knowledge regarding menarche among upper primary school girls and enhance the knowledge with the help of a planned health teaching program.

\section{OBJECTIVES:}

- Assess the level of knowledge among the upper primary girls regarding menarche.

- Determine the association between the level of knowledge regarding menarche and the selected demographic variables.

- Provide a planned health teaching program

\section{RESEARCH DESIGN:}

The research design is the master plan specifying the methods and procedures for collecting and analyzing the needed information in a research study. A non-experimental descriptive design was used for this study.

\section{SAMPLE SIZE:}

The sample for the study consists of 50 upper primary girls studying in STD 6 and 7.

\section{SAMPLING TECHNIQUE:}

Convenient sampling technique.

\section{DATA COLLECTION PROCEDURE:}

Written permission had obtained from the concerned school authority. The objectives of the study had been explained to each subject and a structured questionnaire was used to assess the level of knowledge of upper primary girls regarding menarche. After that a planned health teaching program had provided with the help of LCD.

\section{DATA ANALYSIS:}

The data was analyzed using descriptive and inferential statistics. Frequency and percentage were used for the analysis of demographic variables and knowledge on menarche among upper primary girls. Chi-square was used to determine the association of knowledge with selected demographic variables.

Chi-square $=\Sigma(O-E)^{2}$ Where, $0=$ observed frequency, $E=$ expected frequency

RESULTS:

TABLE - 1

Distribution of girls according to knowledge score regarding menarche

$\mathrm{N}=50$

\begin{tabular}{|c|c|c|c|c|}
\hline KNOWLEDGE GRADE & FREQUENCY & PERCENTAGE & MEAN & STANDARD DEVIATION \\
\hline Good & 7 & $14 \%$ & & \\
\hline Average & 41 & $82 \%$ & & \\
\cline { 1 - 3 } Poor & 2 & $4 \%$ & \multirow{2}{*}{15.36} & \multirow{2}{*}{$15.36 \pm 3.6$} \\
\hline Total & 50 & $100 \%$ & & \\
\hline
\end{tabular}


- $\quad$ Findings revealed that most of the girls (54\%) belonged to 11 years of age and about $74 \%$ of girls belonged to nuclear family. Majority (74\%) of girls do not have elder sister. Religion wise $74 \%$ were Hindus. The mothers of $46 \%$ of girls were found to be educated upto $10^{\text {th }}$ standard.About $84 \%$ of girls were from urban and $16 \%$ from rural area.

- It was found that $14 \%$ had good knowledge, $82 \%$ had average knowledge and only $4 \%$ were reported poor knowledge regarding menarche.

- There was a significant association between knowledge and the demographic variables such as age, educational status of mother, religion.

\section{CONCLUSION:}

Based on the findings of the study it is clear that upper primary school girls having adequate knowledge regarding menarche and the demographic variables such as age, educational status of mother, religion have significant association with knowledge of upper primary school girls. Nurses can utilize this study to give health teaching about puberty, female reproductive system, menstruation, menstrual hygiene. Community health nurses can also adopt this knowledge to spread the health message to community regarding menstruation.

\section{REFERENCES:}

1. Abhijit V B, ShibSekharDatta, Karthiga V. 'Perception and practice regarding menstruation among adolescent school girls in Pondicherry'. The health agenda 2(4) 57-63, 2014.

2. Amrita Bagga, S.Kulkarm. 'Age at menarche and secular tend in Maharashtriangirls'. 44(1-4) 53-57, 2000- http://www.sci.u.szeged.hu/ABS.

3. Aribo E O, Ikempti F J, Nwanygway. 'Menarcheal age in school girls in Calabar, Nigeria'. 7(1), 325-330, 2015.

4. DeepanjaliBehera, MuthuswamySivakami, ManasRanjanBehera. 'Menarche and Menstruation in Rural Adolescent Girls in Maharashtra, India: A qualitative Study'. Journal of health management; 17(4) 510-519, 2015.

5. DG Dambhare, Sanjay.V.Wagh, Jayesh $Y$ Dudha. 'Age at menarche and menstrual cycle pattern among school adolescent girls in central India'. Global Journal of health science; 4(1) 101-105, 2013.

6. Dixit Jagdamba, Dixit Anil Kumar. 'Menarcheal pattern and knowledge of reproductive health in young adolescent girls of village in India'. Global Journal of health science; 4(1) 104-111, 2015.

7. Kusum S Manus, HolyachiSharan Kumar, Badesah, Bheemayya. 'Age at menarche and factors associated among girls of a primary health centre area in Davangere, India'. International Journal of adolescent medicine and health; 7(5) 417-420, 2016.

8. MinnaSaavala, Jacobsen B K. 'Anthropometric measurements on age at menarche and diet in adolescent girls in slum of Nashik, Western India'. International Journal of Adolescent Medicine and health; 27(4)451-458, 2015.

9. Rajkumar Paul, LakeshAgarwal, Sajeev Kumar Gupta, M. Raghavai, Anaj Mittal. 'Belief about menstration, a study from rural Pondicherry'. Indian Journal of medicalspecialities; 2(1) 23-26, 2011.

10. SarithaSomanRadha, VimalaChellappan. 'Age at menarche and its relation withnutritional and socio economic status- A study among adolescent school girls'. International Journal of medical science and public health; 6(4) 776-780, 2015.

11. ShayestehJahanfar, Munn-Sannlye, Isthrinayagy S. Krishnarajah. 'Genetic and enviornmental effects on age of menache, and its relationship with reproductive health in twins'. Indian Journal of human Genetics; 19(2) 245-250, 2013.

12. Villamor E, Martin C, Mora Plazas. 'Vitamin D Deficiency and age at menarche; prospective study'. American Journal of clinical Nutrition; 94 1020-1025 (2011). 